\title{
Ground vibration mitigation by using ballast mat
}

\author{
Huan Yuan', Ruijun Zhu' ${ }^{2}$, Junwei Huang ${ }^{3}$, Junjie $\mathrm{Li}^{4}$, Chao Zou \\ School of Civil and Transportation Engineering, Guangdong University of Technology, Guangzhou, China \\ ${ }^{5}$ Corresponding author \\ E-mail: ${ }^{12416825713 @ q q . c o m,{ }^{2} 747284511 @ q q . c o m,{ }^{3} 1165735644 @ q q . c o m,{ }^{4} 924781909 @ q q . c o m,}$ \\ 56331993@qq.com
}

Received 1 February 2021; received in revised form 13 February 2021; accepted 20 February 2021 DOI https://doi.org/10.21595/vp.2021.21902

Check for updates

Copyright (C) 2021 Huan Yuan, et al. This is an open access article distributed under the Creative Commons Attribution License, which permits unrestricted use, distribution, and reproduction in any medium, provided the original work is properly cited.

\begin{abstract}
The frequently moving subway trains often cause large vibration of the rack buildings especially tall buildings and noise problem, which lead to the discomfort of the occupants. Therefore, it is highly necessary to adopt measures to decrease the vibrations. The finite element model of vehicle-rail-foundation was established by using ABAQUS program, and vibration mitigation ability by using ballast mats was investigated. The results showed that the ballast mat has ability to mitigate train-induced environmental vibrations. The acceleration level can be highly reduced within $30 \mathrm{~m}$ from the track centerline on the ground. Increasing the thickness of the ballast mat and increasing the static foundation modulus can enhance the vibration mitigation effect. The research results can provide references for the train-induced environmental vibration mitigation design.
\end{abstract}

Keywords: ballast mat, subway, finite element.

\section{Introduction}

Ballast mat is made of natural and synthetic rubber, which can mitigate vibration and even achieve the effect of preventing the propagation of vibration. In addition, it can also adjust the rigidity of the track superstructure and prevent excessive wear of the ballast [1]. The use of ballast mats plays an important role in environmental vibration control, which has two reasons. First, many cities are planning or implementing the development of subway superstructures. However, within $30 \mathrm{~m}$ from the track centerline, ground vibration and building vibration have exceeded the limit of relevant vibration standards. The large track stiffness is one of the main causes of environmental vibration and secondary noise. Second, the ballasted track often suffers from diseases such as rapid ballast pulverization, whitening of the ballast bed, serious compaction, and "liquefaction" of the ballast due to insufficient thickness of the ballast bed. These diseases not only greatly increase the workload of track maintenance and repair, but also make the environmental friendliness of rail transportation greatly reduced. Accordingly, it is particularly important to improve and strengthen the ballasted track.

A number of works have shown that ballast mats can effectively reduce the overall rigidity of the ballasted track, reduce wheel-rail impact, extend the track maintenance cycle and reduce track vibration and noise [2]. Costa et al. [3] proposed a numerical study to understand the dynamic behavior of ballast mats by including a train-track-ground model. Sheng et al. [4] built a finite element model of ballastless track of China Railway System and used mats as vibration isolation method to obtain the vibration mitigation effect. Diego et al. [5] proposed a new material for isolation mats and has been proved to be suitable for railway vibration mitigation by measurements. However, the detailed research of ballast mat properties for vibration mitigation is not enough.

In order to discuss the ballast mat properties for vibration mitigation, this paper established a vehicle-rail-foundation numerical model. The propagation characteristics of the vibrations were analyzed in the domains of time to figure out how the vibration mitigation effect will be changed by the thickness and the static foundation modulus of the ballast mat. The research results can enrich the vibration mitigation measures for subway projects that use ballast mat to achieve 
vibration reduction effects.

\section{Establishment of finite element model}

\subsection{Train load}

Wheel-rail forces mainly appear in 3 frequency ranges: (1) relative motion of the train body and suspension in $0.5 \mathrm{~Hz}-10 \mathrm{~Hz}$; (2) It is caused by the spring-back effect of the mass of wheelset on the rail in intermediate frequency range $(30 \mathrm{~Hz}-60 \mathrm{~Hz})$; (3) It is produced by the resistance of the wheel-rail contact surface due to the movement of the rail in high frequency range $(100 \mathrm{~Hz}-140 \mathrm{~Hz})[6]$.

Therefore, it is feasible to simulate the train load with an excitation force function, as shown in Eq. (1):

$F(t)=k_{1} k_{2}\left(P_{0}+P_{1} \sin \omega_{1} t+P_{2} \sin \omega_{2} t+P_{3} \sin \omega_{3} t\right)$,

where $k_{1}, k_{2}$ are the superposition and dispersion coefficient, $P_{0}$ is the static train load; $P_{1}, P_{2}, P_{3}$ are the loads related to the above three frequency ranges.

Let the unsprung mass of the train be $M_{0}$, the load can be defined by Eq. (2):

$P_{i}=M_{0} a_{i} \omega_{i}^{2}$

The relevant parameters of the train are shown in Table 1. According to the calculation conditions, the selected A-type subway train load simulation equation is Eq. (3):

$F(t)=1.08 \times(20+0.3701 \sin 31.42 t+0.6940 \sin 157.08 t+0.2024 \sin 392.7 t)$.

Table 1. Related parameters of subway train

\begin{tabular}{|c|c|}
\hline Bogie wheelbase & $2500 \mathrm{~mm}$ \\
\hline Vehicle distance & $15700 \mathrm{~mm}$ \\
\hline Train length & $22100 \mathrm{~mm}$ \\
\hline Axle weight & $16 \mathrm{t}$ \\
\hline Mass of wheelset & $1500 \mathrm{~kg}$ \\
\hline
\end{tabular}

\subsection{Track model}

The track model consists of steel rails, sleepers and ballast. The track is U75V hot-rolled steel rail, and $60 \mathrm{~kg} / \mathrm{m}$. The rail gauge is $1435 \mathrm{~mm}$; the track bed is a gravel track bed with a thickness of $0.45 \mathrm{~m}$. Table 2 shows the parameters for track model.

Table 2. Related parameters of track structure model

\begin{tabular}{|c|c|c|c|}
\hline & Elastic modulus (GPa) & Poisson's ratio & Density $\left(\mathrm{kg} / \mathrm{m}^{3}\right)$ \\
\hline Rail & 210 & 0.25 & 7850 \\
\hline Concrete sleeper & 30 & 0.2 & 2400 \\
\hline Ballast & 0.3 & 0.35 & 1800 \\
\hline Sub-ballast & 0.3 & 0.35 & 2200 \\
\hline Embankment & 0.1 & 0.30 & 1900 \\
\hline
\end{tabular}

\subsection{Soil model}

The soil model dimension is selected as $130 \mathrm{~m} \times 130 \mathrm{~m} \times 55 \mathrm{~m}$, which is shown in Fig. 2. The vibration caused by the subway train is in a micro vibration, thus the soil model is adopt the linear elastic model. The soil property can be obtained from the results of the geological survey. 


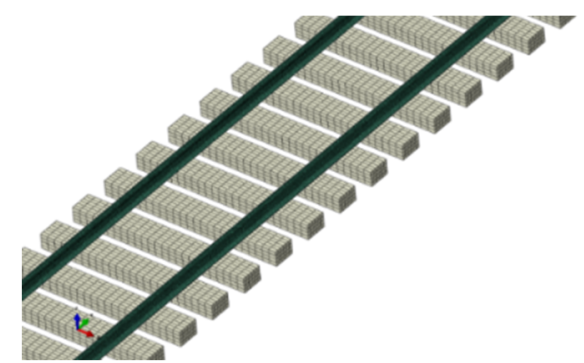

Fig. 1. Finite element model of track and sleeper

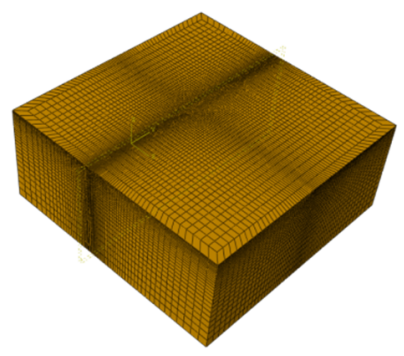

Fig. 2. Foundation soil model

\subsection{Ballast mat}

A ballast mat is set under the ballast. The ballast mat is made of high-quality rubber, wear-resistant, oil-resistant, and ozone-resistant (Fig. 3). Its width is $1500 \mathrm{~mm}$. Its thickness is $27 \mathrm{~mm}$, and the unit area weight is $18 \mathrm{~kg} / \mathrm{m}^{2}$. When the load is $0.020-0.100 \mathrm{~N} / \mathrm{mm}^{2}$, the static foundation modulus is $0.030 \mathrm{~N} / \mathrm{mm}^{3} \pm 15 \%$, and when the preload is $0.060 \mathrm{~N} / \mathrm{mm}^{2}$ and $40 \mathrm{~Hz}$, the dynamic foundation modulus is $0.080 \mathrm{~N} / \mathrm{mm}^{3} \pm 15 \%$. It is assumed that the fixed hysteretic damping value is 0.1 for the mat. Fig. 4 shows the finite element model after adding ballast mat. Ballast mat was inserted between the sub-ballast and embankment.

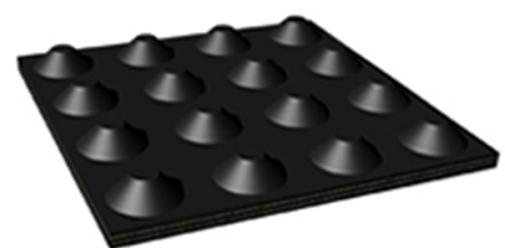

Fig. 3. Ballast mat

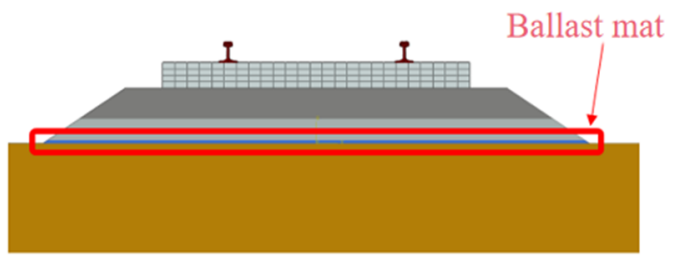

Fig. 4. Finite element model

\subsection{Model verification}

Set the train model to Type A as the load input parameter, compare the calculation results for different distance from the track of the numerical model with field measurement data, and the reliability of the numerical model is verified, as shown in Fig. 5. It can be seen that the calculated value matched well with the measured value, which indicated the established numerical model can better simulate the vibration damping characteristics of ballast mat.

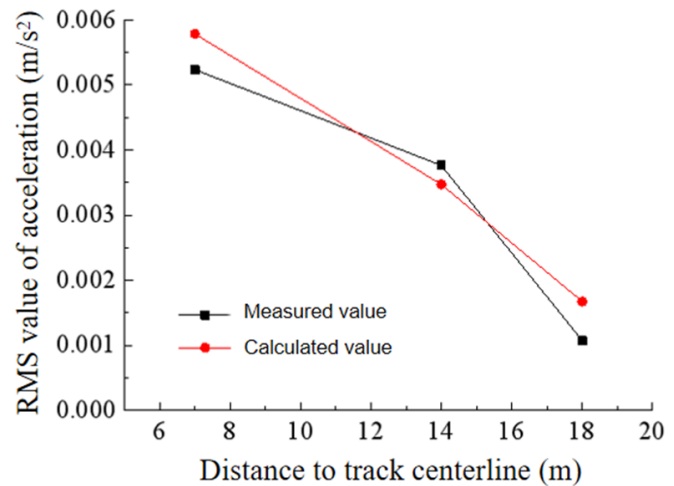

Fig. 5. Model verification

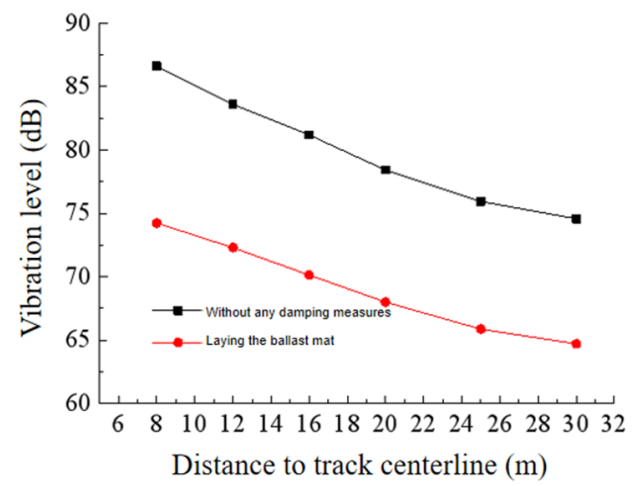

Fig. 6. Ballast mat vibration reduction effect 


\section{Results and discussion}

\subsection{Influence of setting ballast mat}

The vibration mitigation characteristics of setting ballast mat are shown in Fig. 6. It can be seen that the ballast mat can effectively attenuate the vibration. The ground vibration can be reduced by about $10 \mathrm{~dB}$ within $30 \mathrm{~m}$ from the center line of the track, and the attenuation of vibration decreases with the increase of the distance from the center line of track.

\subsection{Impact of the thickness of the ballast mat on vibration reduction effect}

In order to know the influence of the thickness of the ballast mat on vibration mitigation, the thickness of the ballast mat was changed without changing the width and the static foundation modulus, and combined with the actual situation of the ballast mat model, $15 \mathrm{~mm}, 23 \mathrm{~mm}, 27 \mathrm{~mm}$ and $32 \mathrm{~mm}$ are compared and analyzed.

In Fig. 7, the vibration isolation effect of the ballast mat is obvious as the thickness of the ballast mat increases. However, the improvement of the vibration mitigation is not obvious when the thickness is enough. The closer to the track centerline, the increase in the thickness of the ballast mat has a more obvious impact.

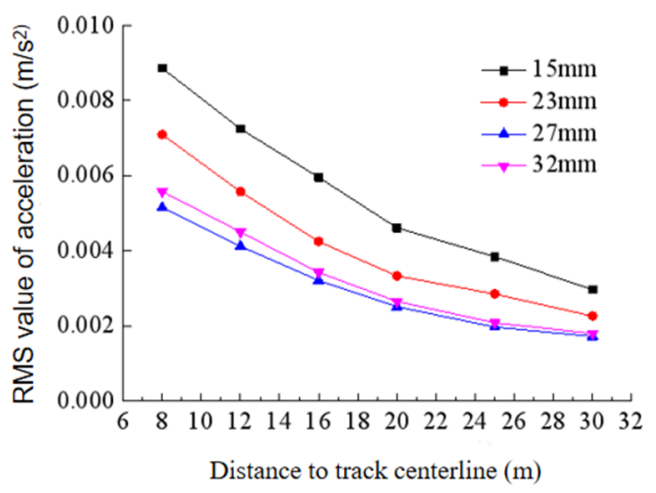

Fig. 7. Vibration mitigation of ballast mats of different thicknesses

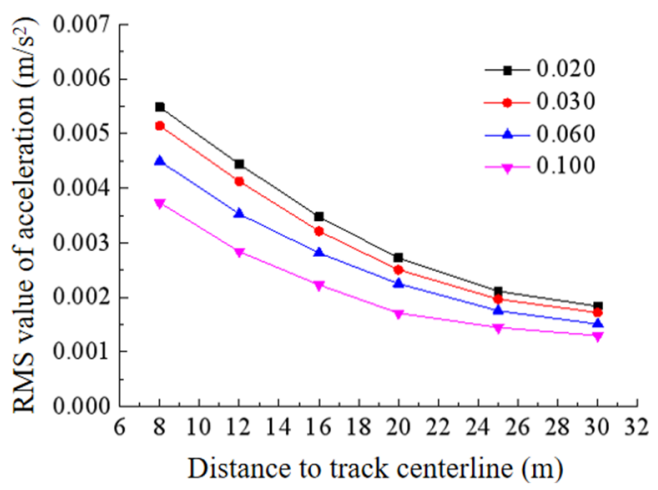

Fig. 8. Vibration mitigation of ballast mats under different static foundation modulus

\subsection{Impact of the static foundation modulus of ballast mat}

To study the effects of the static foundation modulus of the ballast mat on the vibration mitigation, the static foundation modulus of the ballast mat was changed without changing the width and thickness, combined with the actual production situation of the ballast mat, respectively, as shown in Fig. 8.

As the static foundation modulus increases, the vibration mitigation of the ballast mat increases, especially as the closer to the center line of the rail, the increase effect is more obvious. However, at some distance from the center line of the rail, the vibration isolation effect tends to be consistent.

\section{Conclusions}

High-quality natural rubber synthetic ballast mat has the advantages of wear-resistant-oil-resistant, ozone-resistant and weather-resistance. Research on its vibration isolation effect shows:

1) The ballast mat has obvious damping effect on the vibration transmission. Within $30 \mathrm{~m}$ from the track centerline, the ground vibration can be reduced by about $10 \mathrm{~dB}$, and the attenuation of 
vibration decreases with the increase of the distance from the center line of track.

2) Increasing the thickness of the ballast mat and increasing the static foundation modulus has advantage for the vibration mitigation, the closer to the rail center line, the greater the attenuation of vibration level.

\section{References}

[1] Tao Z., Wang Y., Sanayei M., Moore J. A., Zou C. Experimental study of train-induced vibration in over-track buildings in a metro depot. Engineering Structures, Vol. 198, 2019, p. 109473.

[2] Zou C., Wang Y., Moore J. A., Sanayei M. Train-induced field vibration measurements of ground and over-track buildings. Science of the Total Environment, Vol. 575C, 2017, p. 1339-1351.

[3] Alves Costa P., Calçada R., Silva Cardoso A. Ballast mats for the reduction of railway traffic vibrations. Numerical study. Soil Dynamics and Earthquake Engineering, Vol. 42, 2012, p. 137-150.

[4] Sheng X., Zheng W., Zhu Z., Luo T., Zheng Y. Properties of rubber under-ballast mat used as ballastless track isolation layer in high-speed railway. Construction and Building Materials, Vol. 240, 2020, p. 117822.

[5] Diego S., Casado J. A., Carrascal I., Ferreño D., Cardona J., Arcos R. Numerical and experimental characterization of the mechanical behavior of a new recycled elastomer for vibration isolation in railway applications. Construction and Building Materials, Vol. 134, 2017, p. 18-31.

[6] Zou C., Moore J. A., Sanayei M., Wang Y. Impedance model for estimating train-induced building vibrations. Engineering Structures, Vol. 172, 2018, p. 739-750. 